\title{
溶接部ならびに鋳物の透過 $\mathbf{X}$ 線写真にあらわれる影 $\left(\right.$ 第5報) ${ }^{*}$
}

\author{
一影と延性— \\ 渡边統 市** 安 藤 真一郎***

\begin{abstract}
The Mottling Appeared on Radiograph of Weldments
\end{abstract} \\ and Castings ( 5 th Report)
}

-The mottling and ductility-

by Toichi Watanabe**, Shinichiro Ando***

\begin{abstract}
Influence of the mottled appearance on the tensile and bend ductility was investigated. The mottling frequently observed on radiogrphs of austenitic stainless steel weldmetals and castings. Longitudinal weldmetal specimens with different levels of contrast of the mottling were prepared. The results may be summarized as follows.

1. Progr essive increase in the contrast produced a marked decrease in both tensile and bend ductility.

2. Cracks appeared on bend specimens were intergranular. The intergranular cracking strongly suggests that microfissures were present, while such specimens show pronounced mottling.

The results seem to suggest that low density grain boundaries containing such a defect as microfissures may be important concerning the mechanism of the mottled appearance.
\end{abstract}

\section{1. 粕唄}

ステンレス溶接金属ならびに鋳物の透過 X線写真にあ らわれる影飞ついて，前報1,22,3)ではその原因として低 密度粒界説を提唱した。すなわちボイド，マイクロクラ ックあるいわ低融点化合物が粒界にあれば疑固組織特有 の低密度粒界となり，そとでX線が回折して影となって あらわれるというものである.一方あきらかな溶接割れ からあ影の発生することが確認されている4). この影の 発生機構の精細についてはまだ明らかでないが，割れの 形態之関連してX線の入射角あるいは波長などの条件が 満足したときあらわれるあのと考えられる.

低密度粒界あるいは溶接割犺といったいわゆる溶接欠 陥が影の原因であれば，影の機械的性質におよに゙す影響 を明らかにしなくてはならない。この研究はその一睘と してまず引張ならびに曲げ性質について影との関係を追 求したものである.

\section{2. 試料ならびに試験方法}

影のコントラストは溶接金属中のフェライト量と密接 な関係にあり，したがって溶接金属の成分ならびそ溶接 速度によって著しく異ってあらわれる2)．との研究では

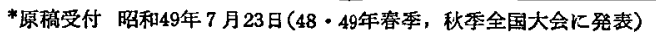

**正 名古屋工莱大学 Member, Nagoya Institute of Technology

***研究当時 名古屋工業大学大学院 Post Graduate, Nagoya Institute of Technology 現在日立造船
}

とういった溶接条件と影の関係を利用して，影のコント ラストの異る溶接試片を造った. 溶接方法は前報2で处 ベた通りである.すなわち，片側 $45^{\circ}$ の開先をつけた板 厚 $6 \mathrm{~mm}$ の18:8ステンレス鎆板を突含せて, 出来る V溝に溶接棒心線をねかせて前進一層 TIG 溶接を行な うというものである. 開先深さは引張試片については $4 \mathrm{~mm}$ とし一方曲げ試片については $3 \mathrm{~mm}$ とした. 溶 接棒としては19：9心線に純ニッケル線を併用するす の, 19:9心線単独のものならびに25:20心線単独のも のがある. Table 1 は用いた溶接棒ならびに母材の化学 成分を示したものである。

溶接は希釈率を約 $70 \%$ とし，同じ溶接棒を用いた場合 は溶接金属の成分がほぼ一定となるようにした。影は成 分上オーステナイトの安定度がますにつれて明瞭にあら われる. 溶接速度は $2 \sim 18 \mathrm{~cm} / \mathrm{min}$ と変化した。溶接 速度が小さい場合フェライト量は少なく，影牥明瞭にあ らわれる傾向にある。

引張試片については同一溶接条件による溶接接手を四 つ用意し, そのうちの二つは溶接のまま, 残りの二つは 溶体化処理を行なってのち試片の製作に供した。引張試 片は溶接線長手方向に探取した全溶接金属よりなるすの でその寸法を Fig. 1 に示す. 一方曲げ試片はこれを溶 接線長手方向に採取し，表曲げ試験を行なった．Fig. 2 はその寸法ならびに曲げ加工の要領を示したものであ る. 
Table 1 Chemical analysis of base metals and filler metals used.

\begin{tabular}{|c|c|c|c|c|c|c|c|c|c|c|}
\hline & JIS & $\mathrm{C}$ & $\mathrm{Si}$ & $\mathrm{Mn}$ & $\mathrm{P}$ & s & $\mathrm{Ni}$ & $\mathrm{Cr}$ & $\mathrm{Cu}$ & $\mathrm{Fe}$ \\
\hline Base metal & $\begin{array}{r}\text { SUS } 304 \\
(18: 8)\end{array}$ & $\leq 0.88$ & $\leqslant 1.00$ & $\approx 2.00$ & $=0.040$ & $\$ 0.030$ & $8.00-10.50$ & $18.00-20.00$ & - & bal. \\
\hline \multirow{2}{*}{ Filler metal } & $\begin{array}{l}\text { D } 308 \\
(19: 9)\end{array}$ & $=0.08$ & $=0.90$ & $\leq 2.50$ & $=0.040$ & $=0.030$ & $9.00-11.00$ & $18.00-21.00$ & - & bal. \\
\hline & VNIWL & 0.026 & 0.06 & 0.15 & - & - & 99.69 & - & 0.06 & 0.011 \\
\hline
\end{tabular}

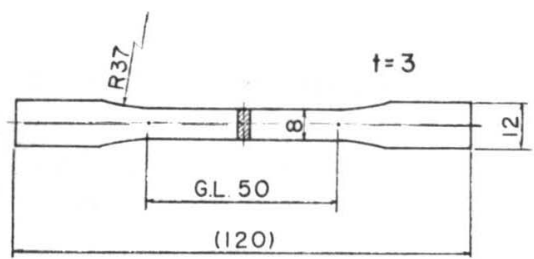

Fig. 1 All-weld-metal tensile-test specimen.
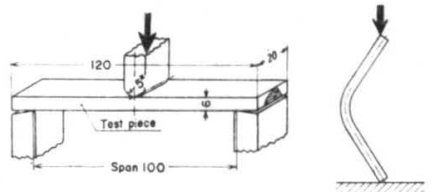

Fig. 2 Bend-test specimen and testing procedure. In the early stage of the test, specimen was bent as centrally loaded simple beam with the weld in longitudinal tension.
曲げ加工中に発生した割れは染色探傷法によって検出 した. 引張, 曲げ試験とすに小型万能試験機を用いて行 ない, 引張速度はすべて $2 \mathrm{~mm} / \mathrm{min}$ とし, 曲げ試験は 少し曲げては表面状況をしらべるという方法を繰返して 加工を進めた.

\section{3. 実験結果ならびに考察}

\section{a. 引張試験}

全溶接金属からなる引張試験片の透過 X 線写真とミク 口組織の一例を Photo. 1 亿示す. X 線写真は試片に整 形後, 引張試験前に撮影したものであり, 組織写真は試 験後の試片断面について得られたものである.とこに例 示した試片は母材 $18 ： 8$, 溶接棒は $19 ： 9$ 心線に純ニッ ケル線を併用したグループに属するものであるが, 写真 でみられるようにフェライト量が増加するにつれて影は コントラストを失う傾向にある．とこで影のコントラス

No. $\mathrm{A} 1-1$
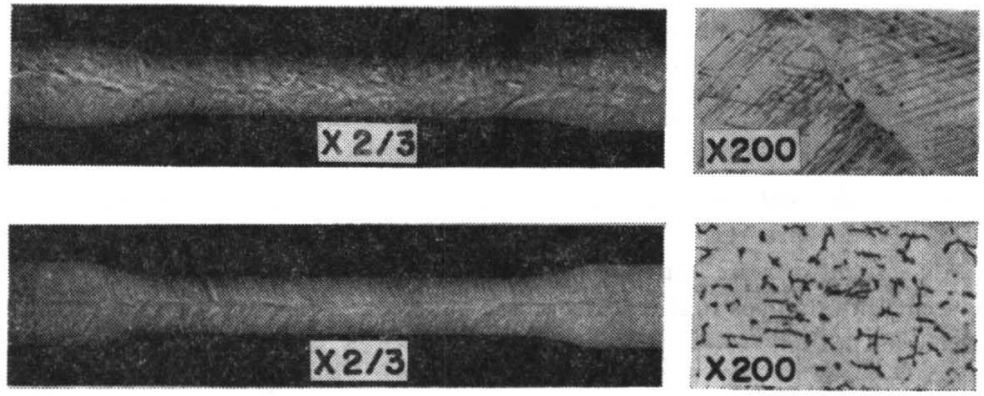

No. A2-1
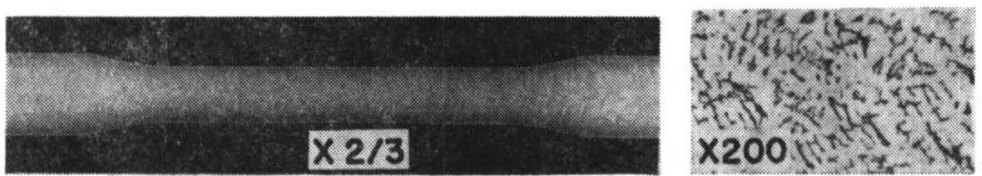

Photo. 1 Some examples of radiograph and micro-structure of all-weld-metal tensile-test specimens in as-welded condition.

welding conditions and others of these specimens are shown in Table 2. Spec. No. A1-1, A2-1 and A3-1 are graded as "High", "Medium" and "Low" respectively, according to contrast of the mottling. Delta ferrite in the structure decreases as the contrast increases. 
トについてとの研究ではとれを "High", “Medium”な らびに “Low” の三段階に区分して示した。試片 No. A1-1 とついていえばその影のコントラストは“High”, No. A2-1 では試片左側の一部にみられる明瞭なかげを 除きその他の部分については “Medium”, No. A3-1 で は “Low”とした.

Tables 2〜4 は用いた溶接棒の異なる各グループの試 片について，それぞれの溶接条件と引張陚験結果を示し たものである. Table 2 に示すグループについてみれば 溶接速度が $3 \mathrm{~cm} / \mathrm{min}$ から $18 \mathrm{~cm} / \mathrm{min}$ と早くなるに つれてフェライト量は増大し，同時に影む先述した三段
階の区分による“High”から“Low”まで変化する. 一方伸びについては各試牒による多少の変動は認められ ながらも大勢としては影がコントラストを失うにつれて 增大する傾问にある. 引張強さは影のコントラストの望 いものがやや低い傾向にあるがその差は少ない。

Tables 3，4 亿示す各グループについては，前者では 影の不明膫な試版が多く，後者では影の明瞭な試片にか たよっている. 各グループ内での影のコントラストの差 が少なく，また伸びの差も少ない，てのためか影と伸び の関係はいずれのグループにおいてああまり明瞭でな い.しかしながら影のより明瞭なすのが伸びもやゃ低い

Table 2 Effect of variations in contrast of the mottling on the tensile properties of stainless steel weld metals:

Longitudinal all-weld-metal specimens in as-welded condition with different levels of the contrast were tested. progressive increase in the contrast produced a marked decrease in tensile ductility and a minor decrease in tensile strength.

base metal, 18:8 stainless steel plate, $6 \mathrm{~mm}$ in thickness. filler metals, 19:9 stainless steel wire, $5 \mathrm{~mm}$ in diameter, plus nickel wire, $0.75 \mathrm{~mm}$ in diameter. TIG.

\begin{tabular}{r|c|c|c|c|c|c|c}
\hline \hline $\begin{array}{c}\text { Spec. } \\
\text { No. }\end{array}$ & $\begin{array}{c}\text { voltage } \\
\text { volts }\end{array}$ & $\begin{array}{c}\text { Current } \\
\text { amperes }\end{array}$ & $\begin{array}{c}\text { Travel } \\
\text { cm/min }\end{array}$ & $\begin{array}{c}\text { Delta ferrite } \\
, 8,\end{array}$ & $\begin{array}{c}\text { Contrast of } \\
\text { the mottling }\end{array}$ & $\begin{array}{c}\text { Elongation } \\
.8, \text { in } 50 \mathrm{~mm}\end{array}$ & $\begin{array}{c}\text { Ultimate } \\
\text { tensile strength } \\
\mathrm{Kg} / \mathrm{mm}^{2}\end{array}$ \\
\hline Al-1 & 15 & 165 & 3 & $0-1$ & High & 44.8 & 56.5 \\
-2 & 15 & 165 & 3 & $0-1$ & High & 34.0 & 56.4 \\
A2-1* & 15 & 240 & 8 & $0-4$ & Medium & 32.4 & 52.2 \\
-2 & 15 & 240 & 8 & $3-4$ & Medium & 52.0 & 62.0 \\
A3-1 & 15 & 320 & 13 & 6 & Low & 53.9 & 58.9 \\
-2 & 15 & 320 & 13 & 5 & Low & 56.1 & 59.9 \\
A4-1 & 15 & 405 & 18 & 6 & Low & 49.9 & 59.9 \\
-2 & 15 & 405 & 18 & 6 & Low & 59.9 & 60.4 \\
\hline
\end{tabular}

* indicates an irregular distribution of ferrite in weld metal

Table 3 Effect of variations in contrast of the mottling on the tensile properties of stainless steel weld-metals.

Longitudinal all-weld-metal specimens in as-welded condition with different levels of the contrast were tested. progressive increase in the contrast produced a minor decrease in tensile ductility and a slight increase in tensile strength.

base metal, 18:8 stainless steel plate, $6 \mathrm{~mm}$ in thickness. filler metal, 19:9 stainless steel wire, $5 \mathrm{~mm}$ in diameter. TIG.

\begin{tabular}{|c|c|c|c|c|c|c|c|}
\hline $\begin{array}{l}\text { Spec. } \\
\text { No. }\end{array}$ & $\begin{array}{l}\text { Voltage } \\
\text { volts }\end{array}$ & $\begin{array}{l}\text { Current } \\
\text { amperes }\end{array}$ & $\begin{array}{l}\text { Travel } \\
\mathrm{cm} / \mathrm{min}\end{array}$ & $\begin{array}{c}\text { Delta ferrite } \\
, 8,\end{array}$ & $\begin{array}{l}\text { Contrast of } \\
\text { the mottling }\end{array}$ & $\begin{array}{l}\text { Flongation } \\
, 8 \text {, in } 50 \mathrm{~mm}\end{array}$ & $\begin{array}{l}\text { UItimate } \\
\text { tensile strength } \\
\mathrm{Kg} / \mathrm{mm}^{2}\end{array}$ \\
\hline-2 & 15 & 145 & 3 & $3-4$ & Medium & 53.4 & 66.8 \\
\hline B2-1 & 15 & 220 & 8 & 5 & Low & 53.8 & 63.3 \\
\hline B3-1 & 15 & 290 & 13 & 6 & Low & 56.2 & 63.3 \\
\hline-2 & 15 & 290 & 13 & 6 & Low & 54.2 & 64.4 \\
\hline$B 4-1$ & 15 & 400 & 18 & 6 & Low & 55.8 & 62.1 \\
\hline-2 & 15 & 400 & 18 & 6 & Low & 56.4 & 61.9 \\
\hline
\end{tabular}


Table 4 Effect of variations in contrast of the mottling on the tensile properties of stainless steel weld-metals.

Longitudinal all-weld-metal specimens in as-welded condition with different levels of the contrast were tested. progressive increase in the contrast affects a little on both ductility and strength.

base metal, 18:8 stainless steel plate, $6 \mathrm{~mm}$ in thickness. filler metal, $25 ; 20$ stainless steel wire, $5 \mathrm{~mm}$ in diameter. TIG.

\begin{tabular}{|c|c|c|c|c|c|c|c|}
\hline $\begin{array}{l}\text { Spec. } \\
\text { No. }\end{array}$ & $\begin{array}{l}\text { Voltage } \\
\text { volts }\end{array}$ & $\begin{array}{l}\text { Current } \\
\text { amperes }\end{array}$ & $\begin{array}{l}\text { Travel } \\
\mathrm{cm} / \mathrm{min}\end{array}$ & $\begin{array}{c}\text { Delta ferrite } \\
\text {, } 8,\end{array}$ & $\begin{array}{l}\text { Contrast of } \\
\text { the mottling }\end{array}$ & $\begin{array}{l}\text { Elongation } \\
, 2, \text { in } 50 \mathrm{~mm}\end{array}$ & $\begin{array}{l}\text { Ultimate } \\
\text { tensile strength } \\
\mathrm{Kg} / \mathrm{mm}^{2}\end{array}$ \\
\hline Cl-l & 15 & 175 & 3 & None & High & 43.4 & 52.7 \\
\hline-2 & 15 & 175 & 3 & None & $\mathrm{High}$ & 36.0 & 54.1 \\
\hline C2-I & 15 & 235 & 8 & None & High & 33.6 & 54.1 \\
\hline-2 & 15 & 235 & 8 & $0-1$ & High & 48.2 & 58.9 \\
\hline C3-1. & 15 & 310 & 13 & $1-2$ & High & 42.2 & 54.8 \\
\hline-2 & 15 & 310 & 13 & $0-3$ & High & 35.2 & 55.4 \\
\hline C4-1 & 15 & 405 & 18 & $3-4$ & Medium & 38.6 & 52.4 \\
\hline-2 & 15 & 405 & 18 & $3-5$ & Medium & 44.4 & 53.6 \\
\hline
\end{tabular}

傾向にある。一方引張強さについては Table 3 に示す 結果では影の明瞭なものにおいてやや強い傾向がみら れ, Table 4 に示す結果では各試片の間での差がほとん ど認められたい.

Fig. 3 は得られた結果を影と伸びの関係について, 用いた溶接棒に関係なく，一括して示したものである. この種の溶接金属では一般に影の明瞭な場合，不明膫な あのにくらべて伸びの低いことがわかる．一力引張強さ については影との関連において系統的な関係はみられな い.すなわちそれぞれのグループにおいて時としては相 反する傾向がみられ，また影の明膫なむのと不明瞭なむ のとの間での強度差も少ない.

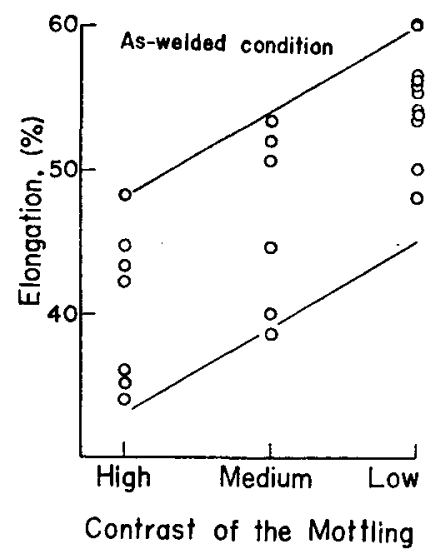

Fig. 3 Relation between tensile ductility and contrast of the mottling for austenitic stainless steel weld-metals in as-welded condition.

The ductility data shown in tables 2,3 and 4 are plotted. Tensile ductility of weld-metal tend to decrease as the contrast increases.
Fig. 3 に示す結果は一応影と伸びの関係を肯定する あのよみられる。しかしながら精細な点についてはまだ 十分あきらかではない，すでに述べたようにこの研究で は影のコントラストの異る試片を製作するにあたって溶 接金属の化学成分ならびに溶接速度をかえてある．との ためコントラストの異なる各試片ではフェライト含有量 が異なり，また結晶粒度も変化していることが考えられ る.一方溶接速度の招そい場合，溶接金属の冷却速度が 小さくしたがって炭化物の析出が考えられ，さらに各グ ループ間での比較を行うについてはそれらの間での成分 の相違という問題がある．こてで各グループ内では溶接 にあたって希釈率を一定にたあってあるので，マクロ的 な成分の相違はないものと期待される.

さてここに列挙した溶接金属中のフェライト量, 結晶 粒度, 析出の有無あるいわ成分の相違などはそのいずれ むが引張性質に影響をおよぼす要因となり得る6のであ る.すなわち第 2 相としてのオーステナイト中のフェラ イト相の存在は強度の増大をまねき, 結晶粒度は降伏応 力あるいわ伸びこ密接な関係にあることが知られてい る.また炭化物の析出は溶接金属の脆化をまねき，一方 成分の変化については成分元素による固溶体強化を考え なくてはならない，影と張張性質の関係を究明するうえ でのこういった問題点を考虑して, 溶接試片に溶体化処 理を加えもってフェライト相を消去した試片についてる たたび引張試験を行なった。

Photo. 2 は溶体化処理を行なったのちの試片につい てその透過 X線写真とミク口組織の一例を示したもので ある：ミクロ組織は引張破断後の陚片断面について得 られたものであり，逐り線があらわれている．写真でみ られるようにこの熱好理によってフェライトはほとんど 
No. A1-3
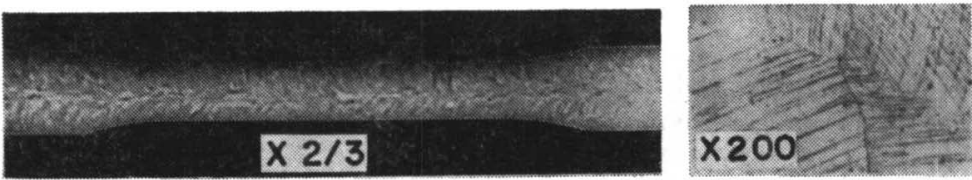

No. A2-3
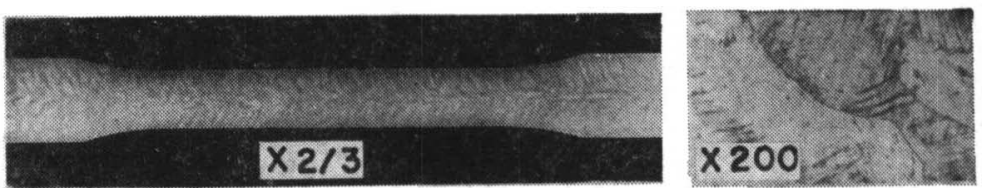

No. $\mathrm{A} 3-3$
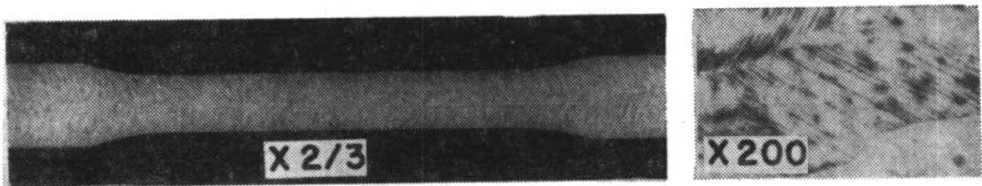

Photo. 2 Some examples of radiograph and micro-structure of all-weld -metal tensile-test specimens in post-weld heat treated condition.

Welding conditions and others of these specimens are shown in table 5. Spec. No. Al-3, A2-3, and A3-3 are graded as "High", "Medium" and "Low", respectively, according to contrast of the mottling. Delta ferrite in the structure is almost disappcared by the heat treatment, whereas the contrast of the mottling remains unchanged.

消滅している. 一方影についてはすでに示した Photo. 1 とくらべてわかるように，乙の程度の熱処理によって そのコントラストはほとんど変化していない. ここで Photo. 1 ならびに Photo. 2 に示した試片はいずれす 母材 $18 ： 8$, 溶接棒としては $19 ： 9$ 心線にニッケル線を 併用するという同じグループに属するあのである.

溶体化処理を加えてフェライト相を消去した試片につ いての引張試験結果を各グループ別にそれぞれ Tables 5〜7 に示した. 表中のフェライト量は試片の両端にお いて熱処理前の組織写真より求めたものである. Tables
5〜7 に示した各グループの試片においてあ, 影のコン トラストの強いものは伸びが低い傾向にある. Fig. 4 は 溶体化処理を加えた試片について, 影と伸びの関係を, 用いた溶接棒に関係なく，一括して示したあのである.

Fig. 4 に示した溶接したままの場合と同様に溶体化処 理を加えたものにあっても，影の明瞭な溶接金属の伸び は不明瞭なものにくらべて低い.

長時間の溶体化処理によってフェライト相を消去しま たもし析出物があったとしてもそれらはオーステナイト 中に再固溶すると期待される試片において，なお影の明

Table 5 Effect of variations in contrast of the mottling on the tensile properties of stainless steel weld-metals.

Longitudinal all-weld-metal specimens in post-weld heat treated condition with different levels of the contrast were tested. progressive increase in the contrast produced a marked decrease in tensile ductility, whereas tensile strength remained nearly constant.

base metal, 18:8 stainless steel plate, $6 \mathrm{~mm}$ in thickness. filler metals, 19:9 stainless steel wire, $5 \mathrm{~mm}$ in diameter, plus nickel wire, $0.75 \mathrm{~mm}$ in diameter. TIG.

\begin{tabular}{|c|c|c|c|c|c|c|c|c|c|}
\hline $\begin{array}{l}\text { Spec. } \\
\text { No. }\end{array}$ & $\begin{array}{c}\text { voltage } \\
\text { volts }\end{array}$ & $\begin{array}{l}\text { Current } \\
\text { amperes }\end{array}$ & $\begin{array}{l}\text { Travel } \\
\mathrm{cm} / \mathrm{min}\end{array}$ & $\begin{array}{l}\text { Delta ferrite } \\
\text {, } 8 \text {, as weld }\end{array}$ & $\begin{array}{l}\text { Post we } \\
\text { heat } t r \\
{ }^{\circ} \mathrm{C}\end{array}$ & $\begin{array}{l}\text { weld } \\
\text { treatment } \\
\quad \text { hrs }\end{array}$ & $\begin{array}{l}\text { Contrast of } \\
\text { the mottling }\end{array}$ & $\begin{array}{l}\text { Elongation } \\
8 \text { in } 50 \mathrm{~mm}\end{array}$ & $\begin{array}{l}\text { Ultimate } \\
\text { tensile strength } \\
\mathrm{kg} / \mathrm{mm}^{2}\end{array}$ \\
\hline$A 1-3$ & 15 & 165 & 3 & $0-1$ & 1050 & 5 & High & 52.9 & 60.4 \\
\hline-4 & 15 & 165 & 3 & $0-1$ & 1050 & 5 & High & 56.2 & $58:-1$ \\
\hline A $2-3$ & 15 & 240 & 8 & $3-4$ & 1050 & 5 & Medium & 57.3 & 58.0 \\
\hline-4 & 15 & 240 & 8 & $4-5$ & 1050 & 5 & Low & 60.0 & 55.5 \\
\hline A $3-3$ & 15 & 320 & 13 & $5-6$ & 1050 & 5 & Low & 60.3 & 56.0 \\
\hline-4 & 15 & 320 & 13 & $5-6$ & 1050 & 5 & Low & 67.7 & 57.2 \\
\hline$A 4-3$ & 15 & 405 & 18 & 6 & 1050 & 5 & Low & 65.3 & 56.0 \\
\hline-4 & 15 & 405 & 18 & 6 & 1050 & 5 & Low & 65.7 & $\therefore 56.0$ \\
\hline
\end{tabular}


Table 6 Effect of variations in contrast of the mottling on the tensile properties of stainless steel weld-metals.

Longitudinal all-weld-metal specimen in post-weld heat treated condition with different levels of the contrast were tested. progressive increase in the contrast produced a marked decrease in tensile ductility, whereas tensile strength remaind nearly constant.

base metal, 18:8 stainless steel plate $6 \mathrm{~mm}$ in thickness. filler metal, 19:9 stainless steel wire, $5 \mathrm{~mm}$ in diameter. TIG.

\begin{tabular}{|c|c|c|c|c|c|c|c|c|c|}
\hline $\begin{array}{l}\text { Spec. } \\
\text { No. }\end{array}$ & $\begin{array}{l}\text { Voltage } \\
\text { volts }\end{array}$ & $\begin{array}{l}\text { Current } \\
\text { amperes }\end{array}$ & $\begin{array}{l}\text { Travel } \\
\mathrm{cm} / \mathrm{min}\end{array}$ & $\begin{array}{c}\text { Delta ferrite } \\
, 8, \text { as weld }\end{array}$ & $\begin{array}{l}\text { Post } \\
\text { heat } \\
{ }^{\circ} \mathrm{C}\end{array}$ & $\begin{array}{l}\text { weld } \\
\text { treatment } \\
\text { hrs }\end{array}$ & $\begin{array}{l}\text { Contrast of } \\
\text { the mottling }\end{array}$ & $\begin{array}{l}\text { Elongation } \\
, 8 \text { in } 50 \mathrm{~mm}\end{array}$ & $\begin{array}{l}\text { Ultimate } \\
\text { tensile strength } \\
\mathrm{kg} / \mathrm{mm}^{2}\end{array}$ \\
\hline Bl-3 & 15 & 145 & 3 & $2-4$ & 1050 & 5 & High & 39.3 & 62.4 \\
\hline-4 & 15 & 145 & 3 & 4 & 1050 & 5 & Medium & 45.2 & 62.2 \\
\hline B2-3 & 15 & 225 & 8 & 5 & 1050 & 5 & Low & 56.2 & 63.4 \\
\hline-4 & 15 & 225 & 8 & 5 & 1050 & 5 & Low & 51.0 & 62.4 \\
\hline B3-3 & 15 & 285 & 13 & 6 & 1050 & 5 & Iory & 52.2 & 58.8 \\
\hline-4 & 15 & 285 & 13 & 6 & 1050 & 5 & Low & 51.6 & 57.6 \\
\hline$B 4-3$ & 15 & 405 & 18 & 6 & 1050 & 5 & Low & 67.8 & 60.6 \\
\hline-4 & 15 & 405 & 18 & 6 & 1050 & 5 & I.OW & 67.6 & 60.0 \\
\hline
\end{tabular}

Table 7 Effect of variations in contrast of the mottling on the tensile properties of stainless steel weld-metals.

Longitudinal all-weld-metal specimens in post-weld heat treated condition with different levels of the contrast were tested. progressive increase in the contrast produced a marked decrease in tensile ductility, whereas tensile strength remained nearly constant.

base metal, 18:8 stainless steel plate, $6 \mathrm{~mm}$ in thickness. filler metal, 25:20 stainless steel wire, $5 \mathrm{~mm}$ in diameter. TIG.

\begin{tabular}{|c|c|c|c|c|c|c|c|c|c|}
\hline $\begin{array}{l}\text { Spec. } \\
\text { No. }\end{array}$ & $\begin{array}{l}\text { voltage } \\
\text { volts }\end{array}$ & $\begin{array}{l}\text { Current } \\
\text { amperes }\end{array}$ & $\begin{array}{l}\text { Travel } \\
\mathrm{cm} / \mathrm{min}\end{array}$ & $\begin{array}{l}\text { Delta ferrite } \\
\text {, } 8 \text { as weld }\end{array}$ & $\begin{array}{l}\text { Post } \\
\text { heat } t \\
{ }^{\circ} \mathrm{C}\end{array}$ & $\begin{array}{l}\text { weld } \\
\text { treatment } \\
\text { hrs }\end{array}$ & $\begin{array}{l}\text { Contrast of } \\
\text { the mottling }\end{array}$ & $\begin{array}{l}\text { Elongation } \\
, 8, \text { in } 50 \mathrm{~mm}\end{array}$ & $\begin{array}{l}\text { Ultimate } \\
\text { tensile strength } \\
\mathrm{Kg} / \mathrm{mm}^{2}\end{array}$ \\
\hline$C 1-3$ & 15 & 175 & 3 & None & 1050 & 3 & High & 43.4 & 54.3 \\
\hline-4 & 15 & 175 & 3 & None & 1050 & 3 & High & 38.8 & 53.3 \\
\hline$C 2-3$ & 15 & .235 & 8 & None & 1050 & 3 & High & 45.4 & 53.9 \\
\hline-4 & 15 & 235 & 8 & None & 1050 & 3 & High & 38.2 & 53.3 \\
\hline$c 3-3$ & 15 & 310 & 13 & $1-2$ & 1050 & 3 & $\mathrm{High}$ & 42.0 & 50.1 \\
\hline-4 & 15 & 310 & 13 & $2-3$ & 1050 & 3 & Medium & 56.4 & 53.8 \\
\hline$c 4-3$ & 15 & 405 & 18 & 4 & 1050 & 3 & Medium & 62.4 & 53.3 \\
\hline-4 & 15 & 405 & 18 & $3-4$ & 1050 & 3 & Medium & 48.8 & 50.8 \\
\hline
\end{tabular}

瞭な場合伸びが低い，乙のことは Fig. 3 に示した現象 すなわち溶接部の透過 X線写真にあらわれる影が明睹な 場合伸びが低下していることについて，フェライト相な いしは考えられる析出物の存在は影響していないてとを 示するのと思われる.一方 Fig. 3 に示した現象に対す る成分の影響について考えてみよう．Fig. 5 は各グル 一プ別に影と伸びの関係を図示したものである．図でみ られるように各グループいずれにおいてす影の明瞭な場 合伸びも低い，乙のととから Fig. 3 に示した結果は成 分の相違によって生じたすのですないてとがわかる.乙 こで各グループ間で比較した場合，影が同じ程度の試片 にあってあそれらの伸びはかなり異なっている。たよえ ば影が同じ “Medium” とされる試片 No. B1-4の伸び
は約45\%であるのに対し試片 No. C4-3 の伸びは $62 \%$ あある．との理由はまだ明らかでないが，まず材質によ る差が考えられ，さらに同じ “Medium”之されるもの にあってもその間にかなりの巾があることなどがあげら れる. また Fig. 3 と Fig. 4 を比較してみると, 影の コントラストが同程度とみられる試片です, 溶体化処理 したものの伸びは溶接のままのあのにくらべてやや高い 傾向にある.一方引張強さは溶体化好理によってわずか に低下する傾向にてる．とれらの現象については焼鈍效 果がその一因であると思われるが，影との関連における その精細はまだあきらかでない，な拓影と引張強さの間 には溶体化処理したものにおいてもあきらかな関係は認 るられない. 


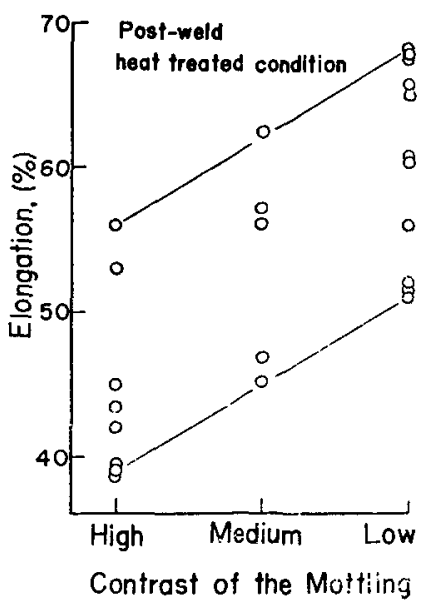

Fig. 4 Relation between tensile ductility and contrast of the mottling for austenitic stainless steel weld-metals in post-weld heat treated condition.

The ductility data shown in tables 5,6 and 7 are plotted. Tensile ductility of weld-metal tend to decrease as the contrast increases.

Fig. 6 は Nos. B1-3, B2-3, C1-3, C2-3 の各試片に ついてそれぞれの結晶粒度をスケッチして示したもので ある. 試片はいずれあ溶体化処理してあり, 引張試験後 の試片断面について得られたすのである. No. B1-3 上 No. C1-3 は亡もに溶接速度 $3 \mathrm{~cm} / \mathrm{min}$ 亡小さく，し たがって結晶籹はいずれあかなり大きい。これらの試片 は Tablẹs 6,7 に示したように溶接したままの状態で のフェライト量が少くしたがって影は明膫である。一方 No. B2-3 と No. C 2-3 はと6に溶接速度が $13 \mathrm{~cm} /$

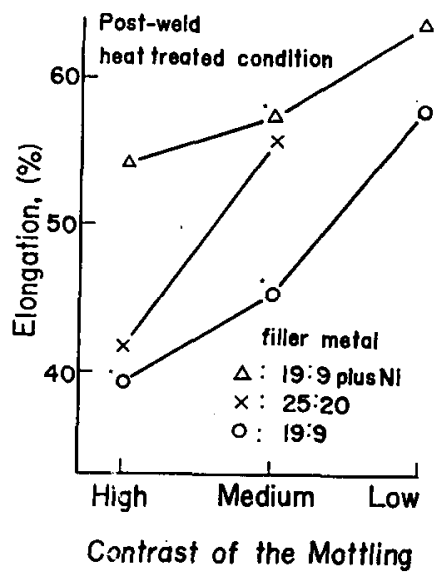

Fig. 5 Influence of composition variations of weldments on the relation between the ductility and the contrast.

Tensile ductility of weldments tend to decrease, in either case, as the contrast increases.

The ductility data shown in tables 5,6 and 7 are plotted, respectively. All-weld-metal specimens in post-weld heat treated condition. Average of several test values except $*$ indicates single result.

min と大きくしたがって結晶粒はいずれあかなり小さ い. 影は No. C 2-3 が明膫であり, No. B2-3 は不明瞭 である.ここで No. B1-3 と No. C1-3 あるいわ No. B2-3 と No. C 2-3 の粒度をくらべてみるとそれぞれ の溶接速度が同じであるためかいずれすほぼ同程度であ る.

Fig. 6 に示した四つの試片について粒度と影と伸び

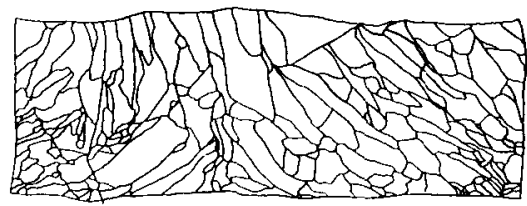

NO.BI-3, Elong. 39.3 (\%)

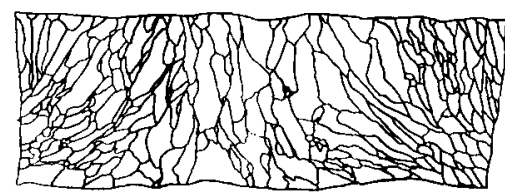

NO.B2-3. Elong. 52.6(\%)

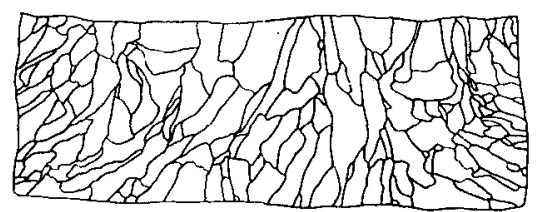

NO.Cl-3, Elong. 43.4(\%)

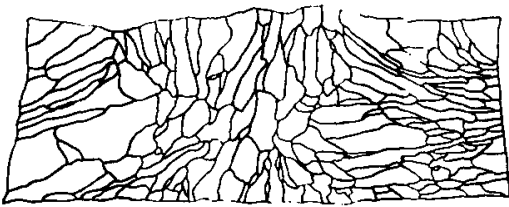

No.C2-3. Elong. 45.4 (\%)

Fig. 6 Influence of grain size of all--weld-metal specimens on the ductility.

There is a considerable difference in both grain size and ductility between two specimens of Spec. No. B1-3 and Spec. No. B2-3, while a considerable difference in grain size and a minor difference in ductility arc noticeable between the specimens of Spec. No. C1-3 and Spec. No. C2-3. The result indicates that the grain size does not affects on the tensile ductility. Sketches, $\times 9$. 
の関係をしらべてみよう. まず No. B1-3 と No. B2-3 についてみればてれらの間で影は “High” から “Low” に，伸びは $39 \%$ から56\%に増大しまた結晶粒あかなり小 さくなっている. 一方 No. C1-3 と No. C2-3 の間で は影のコントラスト，伸びのいずれあがほとんど変らず 結晶粒のみが変化している. No. B2-3 が No. C 2-3 に くらべて伸びが大きいのは結晶粒が小さくなったためで はなく,むしろ影が “High” から “Low” に変ったため であるとみるのが妥当であると思われる.すなわち本実 験の範囲では溶接速度のちがいによる結晶粒度の相違は 伸びに直接影響しないむのと考えられる.

Fig. 3 亿示した結果すなわち影のコントラストの強 い場合伸びが低下しているという現象は，フェライト相 あるいは析出物の存在, 成分, 結晶粒度の相違などに起 因するものではなく，影のコントラストに直接関係する あのであるといえよう．とのことはそれ自体興味ある現 象であるととあに，影の発生機構としての低密度粒界説 を支持するものであると考えられる.

\section{b. 曲げ試験}

Table 8 は19：9ならびに25：20溶接棒心線 $(4 \phi)$ を 用いた溶接試片についての表曲げ武験結果を示したあの である. 試片 Nos. D-1, 2 は19：9 心線を, Nos. E-1, 2,3 は $25: 20$ 心線を用いたものであり, 母材はいずれ
あ18: 8 ステンレス鋼板 $(t=6 \mathrm{~mm})$ である.

試片 No. D-1 は完全オーステナイト組織であり, 影 は明瞭である. との試片は曲げ角度 $60^{\circ}$ ですでに割れを 発生し,さらに曲げ加工が進むにつれて割れはその大さ 之数を増大した. 一方同一成分からなる試片 No. D-2 は溶接速度が $8 \mathrm{~cm} / \mathrm{min}$ と早いため $4 \sim 5 \%$ の ラ イト相を含み, 影は不明瞭である. この試片は密着曲げ にいたるもなお割れを発生しなかった. Photo. 3 は試 片 No. D-1 に発生した割れを示したあのである. 写真 でみられるように割れは粒界割れであり, 表面に達する あのあまた内部に停留するあのあある.

溶接棒として25：20を用いた武片 Nos. E-1, 2, 3 亿 ついても試片 Nos. D-1, 2 の場 合之同様の傾向がみら れる.すなおち影の明瞭な試片においてその延性は低下 している. ただての場合はオーステナイトがより安定で あるため, 溶接速度 $11 \mathrm{~cm} / \mathrm{min}$ の試片 No. E-2 にあ ってあフェライト量は $1 \sim 2 \%$ と少なく, 影も明瞭であ る. 一方との試片の割れ発生の時期は, 影のコントラス 卜において同程度とみられる試片 No. E-1 にくらへて 著しくおそい. 曲げ角度 $180^{\circ}$ にいたってはじめて割れの 発生が認められた。 なお同一成分からなる試片 No. E-3 はフェライトを約 $5 \%$ 含み, 影は不明瞭であり, 密着曲 げにいたってあ割れを発生しなかった。

Table 8 Effect of variations in contrast of the mottling on the bend ductility of stainless steel weld metals. An increase in the contrast produced a marcked decrease in bend ductility.

\begin{tabular}{|c|c|c|c|c|c|c|c|c|}
\hline $\begin{array}{l}\text { Spec. } \\
\text { No. }\end{array}$ & $\begin{array}{l}\text { Base } \\
\text { metal }\end{array}$ & $\begin{array}{l}\text { Filler } \\
\text { metal }\end{array}$ & $\begin{array}{l}\text { Voltage } \\
\text { volts }\end{array}$ & $\begin{array}{l}\text { Current } \\
\text { amperes }\end{array}$ & $\begin{array}{l}\text { Travel } \\
\mathrm{cm} / \mathrm{min}\end{array}$ & $\begin{array}{l}\text { Delta ferrite } \\
\text { content, } 8 \text {, }\end{array}$ & $\begin{array}{l}\text { Contrast of } \\
\text { the mottling }\end{array}$ & $\begin{array}{l}\text { Bend angle at } \\
\text { which cracks } \\
\text { were detected, degrees }\end{array}$ \\
\hline$D-1$ & $18: 8$ & $19: 9$ & 15 & 140 & 2 & None & $\mathrm{High}$ & 60 \\
\hline$D-2$ & $18: 8$ & $19: 9$ & 15 & 210 & 8 & $4-5$ & Low & No cracks \\
\hline$E-1$ & $18: 8$ & $25: 20$ & 15 & 210 & 3.6 & None & High & 63 \\
\hline$E-2$ & $18: 8$ & $25: 20$ & 15 & 260 & 11 & $1-2$ & High & 180 \\
\hline$E-3$ & $18: 8$ & $25: 20$ & 15 & 400 & 18 & 5 & Low & No cracks \\
\hline
\end{tabular}
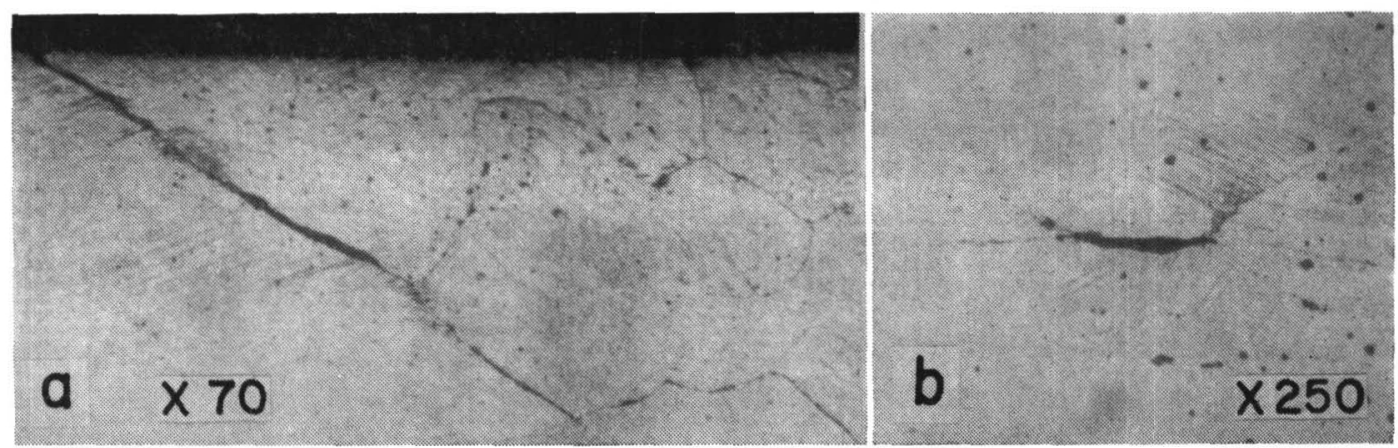

Photo. 3 Intergranular cracks appeared in a bend test specimen of Spec. No. D-1. 
曲げ試験結果について興味深いのは影の明瞭な場合曲 げ延性が低いこと，発生した割れはいずれる精界割れで あり場合によってはかなり早い時期から発生すること あるいわ影のコントラストがほぼ同じ程度である試片 No. E-1 と No. E-2 において割れ発生の時期にかなり のずれが認められるととなどである．影の明瞭な試片に おいて延性の低いことは引張試験結果についてもみられ たととろであり，この点については引張，曲げ両試験結 果は一致した傾向を示している，一方常温における曲げ 試験において粒界割れをしかむかなり早い時期に発生し たことは，粒界にたとえばマイクロクラックのような溶 接欠陌が潜在することを示唆するものと思われる.ここ で組織が完全オーステナイトであるステンレス溶接金属 についてマイクロクラックを確認しあるいはその存在を 示唆した報告あある5。.なおこういった割れを発生しや すい試片において影は明膫にあらわれるのであるから， 得られた曲げ試験結果は影の発生機棈としての低密度粒 界説を支持するあのといえよう. また影のコントラスト が同じ程度である試片間において割れ発生時期にかなり のずれが認められたととは，引張試験の項でも述べたよ うに，影のコントラストと延性を結びつけて考える場合 その間にある程度の巾を見込む必要のあることを示する のと思われる.

\section{4. 結}

論

オーステナイト系ステンレス溶接金属の透過 $\mathrm{X}$ 線写真 にあらわれる影と引張ならびに曲げ性質の関係をしらべ た. 得られた結果は次の通りである。

1. 影の明瞭な試片では影の不明瞭なすのにくらべて
引張，曲げ延性ともに著しく低下している．この延性の 低下はフェライト相の存在あるいわ化学成分, 結晶粒度 の相違なよ゙によるものではなく，影のコントラストに直 接関連したものと思われる。

2. 影の明瞭な試片において曲げ試験中に発生した割 れはいずれあ粒界割れであった。割れは場合によっては 試験中かなり早い時期に発生する，とのととは影の明瞭 な試片についてその粒界にはたとえばマイクロクラック のような溶接欠宿が潜在するととを示唆するものと思わ れる.

3. 研究結果は影の発生機構としての低密度粒界説す なわちボイド, マイクロクラックあるいは低密度の不純 物が粒界にあればこれが影の発生源になるという考え方 を支持するあのであると考えられる。

4. 影のコントラストが同じ程度であるとみられる試 片間において延性にかなりの差がみられた，影のコント ラストと延性を結びつけて考える場合，そこにある程度 の余裕を見込む必要のあることを示すあのと思われる.

5. 影のコントラストと引張強さの間には明暸な関係 は認められなかった。

\section{文献}

1）海边：溶接部ならびに物な透渦 X線 写真にあらわれる影（第 1 報)，本蒜，41-7，(1972）792 800

2）海边，田中：间上(第 2 報)，本誌，43-1 (1974)，12 22

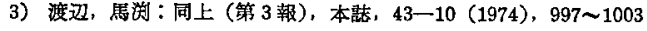

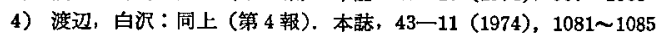

5) G.E. Linnert: Welding type 347 Stainless Steel piping and tubing. Welding research council bulletin series, No. 43,54 (U.S. A.) 